Boise State University

ScholarWorks

Psychological Sciences Faculty Publications and Presentations

10-1-2019

\title{
Masculinity and Suicidal Desire in a Community Sample of Homeless Men: Bringing Together Masculinity and the Interpersonal Theory of Suicide
}

Matthew C. Genuchi

Boise State University

Users are reminded that this article is protected by copyright and reuse is restricted to non-commercial and no derivative uses. Users may also download and save a local copy for the user's personal reference.

Genuchi, M.C. "Masculinity and Suicidal Desire in a Community Sample of Homeless Men: Bringing Together Masculinity and the Interpersonal Theory of Suicide", The Journal of Men's Studies, 27(3), pp. 329-342. Copyright (C) 2019, SAGE. Reprinted by permission of SAGE Publications. https://doi.org/10.1177/1060826519846428. The content of this document may vary from the final published version. 


\title{
Masculinity and Suicidal Desire in a Community Sample of Homeless Men: Bringing Together Masculinity and the Interpersonal Theory of Suicide
}

\author{
Matthew C. Genuchi \\ Boise State University
}

\begin{abstract}
Men's high suicide death rates are likely associated with a range of factors, notably men's conformity to predominant masculine gender role norms and men's gender-related attitudes towards suicide death based on those norms. The purpose of this study was to investigate how two models integrating men's conformity to hegemonic masculine gender role norms, perceived burdensomeness, and thwarted belongingness predict the existence and severity of suicidal ideation in a sample of men at high risk for suicide, homeless men. The study results indicated that multiple norms were predictive of the existence or severity of suicidal ideation while perceived burdensomeness predicted both suicide ideation and the severity of ideation.
\end{abstract}

Keywords: hegemonic masculinity, suicide, perceived burdensomeness, thwarted belongingness

Suicide is a highly concerning cause of mortality in men as suicide rates are higher for men than women in most countries worldwide (Joiner, 2005; World Health Organization, 2015). In 2015 suicide was the tenth leading cause of death in the United States and the seventh leading cause of death in men [Centers for Disease Control and Prevention (CDC), 2015]. While the high frequency of suicide death in men is certainly impacted by men's greater tendency to use more violent and therefore lethal means of suicide (Callanan \& Davis, 2012), the discrepancy between men and women in suicide death rates is associated with a range of other factors, notably men's conformity to predominant masculine gender role norms (Burns \& Mahalik, 2011; Pirkis et al., 2017) and men's gender-related attitudes towards suicide death based on those norms (Canetto \& Safinofsky, 1998; Coleman, Kaplan, \& Casey, 2011).

For example, men are more likely than women to report social disapproval for attempting but not dying from suicide (Rich, Kirkpatrick, Bonner, \& Jans, 1992), a belief that suicide is a powerful act (Lewis \& Shepeard, 1992), a man's death by suicide is less wrong than a woman's death (Deluty, 1988), support for the right to die by suicide (Marks, 1988), and more positive attitudes towards various suicidal behaviors (Dahlen \& Canetto, 2002). Other research, explicitly focused on relationships between masculine norms and suicide in samples of men has indicated that men's stronger conformity to hegemonic masculine gender role norms is related to suicidal ideation (Coleman, 2015; Pirkis, 2016), recent suicide attempts (Easton, Renner, \& O'Leary, 2013), and an acquired capability for suicide (Grenato, Smith, \& Selwyn, 2015).

Recent research on the interpersonal theory of suicide has also illuminated that acquiring the capability for suicide in combination with experiencing the desire to die, which is composed of the interpersonal-psychological factors of perceived burdensomeness and thwarted belongingness, substantially increases the likelihood of suicide (Chu et al., 2017; Joiner, 2005; Van Orden et al., 2010). The acquired capability for suicide is primarily developed by repeated exposures to physically painful and fearful experiences, which results in habituation to the pain and fear associated with death (Joiner, 2005; Smith \& Cukcrowicz, 2010). Suicidal desire is then influenced by one's perception that one is a burden to others (perceived burdensomeness) and disconnected from others (thwarted belongingness), (Van Orden et al., 2010).

Limited research has been conducted on the relationships between hegemonic masculine norms and the interpersonal theory of suicide. However, in work specific to men and masculinity, Grenato, Smith \& Selwyn (2015) have indicated that men who conform more strongly to some masculine norms also report a greater acquired capability for suicide. Little else is known about how conformity to masculine gender role norms and the interpersonal-psychological risk 
factors of perceived burdensomeness and thwarted belongingness occur in populations of men that are at high risk for suicide. Therefore, a study that includes an examination of how gender conformity and interpersonal-psychological risk factors predict suicidal ideation in men integrates a number of factors associated with men's suicide risk.

The purpose of this study was to examine how conformity to hegemonic masculine gender role norms and the interpersonal-psychological factors that influence suicidal desire (perceived burdensomeness and thwarted belongingness) predict suicidal ideation in a sample of men at high risk for suicidal ideation, homeless men. The results of this study were expected to provide insight as to how collectively these variables might inform the prediction of the risk for and severity of suicidal ideation. Furthermore, the process of identifying gender-related and interpersonal risk factors for suicide in men with histories of suicidality may provide valuable information in future identification of more specific factors of men who are at greater risk for suicide.

Based on existing literature on men's conformity to hegemonic masculine gender role norms and the interpersonal theory of suicide, several hypotheses were developed. First, based on existing work by Pirkis et al. (2017) and Genuchi (2018), we hypothesized that the masculine norms of self-reliance, playboy, and violence would predict suicidal ideation in men, even when controlling for demographic and psychiatric covariates. Secondly, consistent with a robust literature on the interpersonal theory of suicide, we hypothesized that experiencing thwarted belongingness and perceived burdensomeness would also predict which men reported suicidal ideation. Finally, we hypothesized that these variables would not only predict the existence of suicidal ideation but also that the variables of self-reliance, playboy, violence, perceived burdensomeness, and thwarted belongingness would predict increased severity of suicidal ideation in the group of men experiencing suicidal ideation, even when accounting for demographic and psychiatric covariates.

\section{Method}

\section{$\underline{\text { Participant Recruitment and Data Collection }}$}

Homeless men were recruited for this study due to their substantially higher risk for suicidal ideation compared to the general population (Eynan, et al., 2002; Noel et al., 2016). The original study sample consisted of 112 homeless, male participants living in a metropolitan area (estimated population 691,421; Hyer, 2017) of the mountain west United States. Participants were recruited from a downtown, non-profit agency that provides a range of resources such as vocational training, clothing, and meals for homeless individuals. Because of the transient nature of this specific population, the resource center was considered a location in which a higher concentration of homeless men would consistently congregate. Participants were offered a $\$ 20$ gift card for participation in the study and completed hard copies of all self-report survey measures in groups within a large room at the resource center. The final sample included independent groups of participants that completed the measures during one of three separate group administrations.

After participation in the study and completion of measures, participant surveys were screened by researchers for psychotic symptoms using the psychosis scale of the Psychiatric Diagnostic Screening Inventory (Zimmerman, 2002), and responses from individuals that endorsed more than three items on the six-item scale were excluded. Additionally, one individual completed a partial questionnaire before the researchers discovered that he had a great deal of difficulty reading in English; therefore, his responses were also excluded. The final sample was 94 homeless men. See Table 1 for more specific sample characteristics across groups of suicide ideators and non-ideators.

\section{Measures and Important Variables}

Demographic Questionnaire. This questionnaire included items that assessed participant gender, race/ethnicity, age, sexual orientation, relationship status, income, and employment.

Thwarted Belongingness and Perceived Burdensomeness. The Interpersonal Needs Questionnaire (INQ-15; Van Orden, Cuckrowitz, Witte, \& Joiner, 2012) was used to assess participants' levels of thwarted belongingness and perceived burdensomeness. The INQ-15 is a 15-item self-report measure developed to assess the two factors of the of the interpersonal theory of suicide, thwarted belongingness and perceived burdensomeness. Five of the INQ-15 items measure belongingeness (e.g., "These days other people care about me") and 10 items measure burdensomeness (e.g., "I think I'm a burden on society"). Respondents must rate how true each statement currently is on a on a 7-point Likert scale. The INQ-15 has demonstrated sound construct validity, concurrent validity with other measures of suicidality, and predictive validity of future suicidal ideation (Van Orden et al., 2012). 
Psychiatric Symptoms. The Psychiatric Diagnostic Screening Questionnaire (PDSQ; Zimmerman, 2002) is a 126item self-report measure that screens symptoms of 13 psychological disorders. The PDSQ subscales have demonstrated good to excellent internal consistency reliability $(\alpha=.73-.95)$ and test-retest reliability $(r=.66-.98)$, as well as sufficient convergent and discriminant validity with similar and different measures (Zimmerman \& Mattia, 2001). The PDSQ has also been shown to correspond with actual diagnoses of clinical syndromes with a high degree of accuracy $(89.3-97.1 \%$ ), (Zimmerman \& Sheeran, 2003). Additionally, The PDSQ psychosis scale was used to screen surveys for participants likely experiencing high levels of psychosis. The PDSQ psychosis scale has been shown to effectively discriminate between outpatients with and without psychotic disorders (Zimmerman, 2002).

Conformity to Hegemonic Masculine Norms. The Conformity to Masculine Norms Inventory-46 (CMNI-46; Parent \& Moradi, 2009) assesses respondent conformity to dominant masculine gender role norms in the United States along nine factors: winning, emotional control, risk-taking, violence, power over women, playboy, self-reliance, primacy of work, and heterosexual self-presentation. The CMNI-46 has demonstrated good to excellent internal consistency reliability $(\alpha=78-.91)$ as well as sufficient convergent $(r=.24-.94)$ and discriminant validity ( $r=-.03$ to .48$)$, (Parent \& Moradi, 2009; Parent \& Moradi, 2011).

Suicidal Ideation. The Beck Scale for Suicidal Ideation (BSS; Beck \& Steer, 1993) is a 21-item self-report inventory designed to measure the severity of suicidal ideation in adults and adolescents. The BSS has demonstrated good psychometric properties with excellent internal consistency $(\alpha=.87-.90)$ and moderate test-retest reliability $(r=.54)$, (Beck, Steer, \& Ranieri, 1988). The BSS has also shown sufficient concurrent validity through correlating with other measures of suicidal ideation (Beck, Steer, \& Ranieri 1988).

\section{Results}

\section{$\underline{\text { Participant Characteristics }}$}

The participants were primarily white (74.5\%), single never-married (54.5\%), heterosexual (83.6\%), and unemployed (81.9\%). Complete demographics and descriptive statistics of the sample, divided into groups of suicide ideators and non-ideators, are presented in Table 1. 
This is an author-produced, peer-reviewed version of this article. The final, definitive version of this document can be found online at The Journal of Men's Studies, published by SAGE Publications. Copyright restrictions may apply. doi: 10.1177/1060826519846428

Table 1

Descriptive Statistics and Sample Characteristics of Participants with and Without Suicidal Ideation

\begin{tabular}{|c|c|c|c|c|}
\hline Variable & $\begin{array}{l}\text { Ideators } \\
(n=55)\end{array}$ & & $\begin{array}{l}\text { Non-Ideators } \\
(n=39)\end{array}$ & \\
\hline & Mean & $S D$ & Mean & $S D$ \\
\hline Income & $\$ 6117.08$ & 7297.96 & $\$ 6167.56$ & 7001.57 \\
\hline INQ-15 Burdensomeness & 17.63 & 10.83 & 10.22 & 6.27 \\
\hline INQ-15 Belongingness & 39.35 & 14.16 & 32.64 & 11.71 \\
\hline CMNI-46 Winning & 8.32 & 3.78 & 8.89 & 3.23 \\
\hline $\begin{array}{l}\text { CMNI-46 Emotional } \\
\text { Control }\end{array}$ & 9.92 & 3.68 & 8.57 & 3.97 \\
\hline CMNI-46 Risk-taking & 8.39 & 4.54 & 6.37 & 3.02 \\
\hline CMNI-46 Violence & 9.24 & 4.63 & 9.64 & 3.93 \\
\hline $\begin{array}{l}\text { CMNI-46 Power Over } \\
\text { Women }\end{array}$ & 3.41 & 2.13 & 3.20 & 2.15 \\
\hline CMNI-46 Playboy & 4.84 & 2.51 & 4.30 & 2.47 \\
\hline CMNI-46 Self-reliance & 7.99 & 2.95 & 5.49 & 2.57 \\
\hline $\begin{array}{l}\text { CMNI-46 Primacy of } \\
\text { work }\end{array}$ & 5.91 & 2.54 & 6.23 & 2.67 \\
\hline $\begin{array}{l}\text { CMNI-46 Heterosexual } \\
\text { presentation }\end{array}$ & 10.33 & 3.92 & 10.50 & 4.92 \\
\hline BSS & 9.13 & 8.25 & 0 & 0 \\
\hline PDSQ Depression & 10.32 & 5.89 & 5.81 & 4.86 \\
\hline $\begin{array}{l}\text { PDSQ Posttraumatic } \\
\text { Stress }\end{array}$ & 7.38 & 5.30 & 5.72 & 5.76 \\
\hline $\begin{array}{l}\text { PDSQ Eating Disorder } \\
\text { Behaviors }\end{array}$ & 1.27 & 1.96 & 1.47 & 1.92 \\
\hline $\begin{array}{l}\text { PDSQ Obsessive } \\
\text { Compulsive Disorder }\end{array}$ & 1.56 & 1.96 & 1.63 & 3.18 \\
\hline PDSQ Panic Disorder & 3.11 & 2.51 & 1.39 & 2.36 \\
\hline PDSQ Agoraphobia & 3.04 & 3.64 & 2.32 & 2.62 \\
\hline PDSQ Social Phobia & 4.27 & 3.95 & 3.03 & 3.54 \\
\hline PDSQ Alcohol Abuse & 2.00 & 2.46 & 1.36 & 2.02 \\
\hline PDSQ Drug Abuse & .79 & 1.66 & .77 & 1.51 \\
\hline $\begin{array}{l}\text { PDSQ Generalized } \\
\text { Anxiety }\end{array}$ & 5.31 & 3.90 & 3.37 & 3.27 \\
\hline PDSQ Somatization & 1.44 & 1.19 & 1.01 & 1.07 \\
\hline
\end{tabular}




\begin{tabular}{|c|c|c|c|c|}
\hline PDSQ Hypochondriasis & 1.25 & 1.45 & .69 & 1.28 \\
\hline PDSQ Psychosis & 1.23 & 1.09 & 1.01 & 1.02 \\
\hline & $n$ & $\%$ & $n$ & $\%$ \\
\hline Heterosexual & 46 & 83.6 & 36 & 92.3 \\
\hline Gay & 3 & 5.5 & 2 & 5.1 \\
\hline Bisexual or Other & 6 & 9.1 & 1 & 2.6 \\
\hline White & 41 & 74.5 & 34 & 87.2 \\
\hline Latino/a & 3 & 5.5 & 1 & 2.6 \\
\hline African American & 3 & 5.5 & 2 & 5.1 \\
\hline $\begin{array}{l}\text { Hawaiian, Pacific } \\
\text { Islander, Native } \\
\text { American }\end{array}$ & 3 & 5.4 & 1 & 2.6 \\
\hline $\begin{array}{l}\text { Mixed Race or Other } \\
\text { Race }\end{array}$ & 5 & 9.1 & 1 & 2.6 \\
\hline Employed & 10 & 18.1 & 5 & 12.8 \\
\hline Single-Never Married & 30 & 54.5 & 16 & 41 \\
\hline Married & 4 & 7.3 & 2 & 5.1 \\
\hline Divorced & 12 & 21.8 & 13 & 33.3 \\
\hline Other & 9 & 16.4 & 8 & 20.5 \\
\hline
\end{tabular}

Out of the 94 individuals in the final sample, 39 (41.49\%) reported some degree of suicidal thoughts or behavior, which is consistent with other samples of homeless men (Desai, Liu-Mares, Dausey, \& Rosencheck, 2003; Susser, Struening, \& Conover, 1989). A significant number of participants reported a history of at least one suicide attempt (31.9\%), and that within the past week they had considered ways of death by suicide (16\%), experienced frequent thoughts of suicide (13.9\%), endorsed a weak or no wish to live (19.2\%), and had made some preparations for suicide $(7.4 \%)$.

\section{Analyses}

Data collected on suicidal ideation tends to include many individuals that report no suicidal ideation. Because of the statistical issues presented with zero-inflated suicide data, suicide researchers frequently examine predictive models involving suicide as a categorical variable. However, such categorization of suicide does not allow for analyses based on suicide severity. Therefore, both multiple logistic and multiple linear regression were used to determine which predictor variables were associated with current suicidal ideation $(\mathrm{BSS}>0)$ and which predictors were associated with increased severity of suicidal ideation.

Mean comparisons across all variables were conducted to examine which variables are significantly different between suicide ideators and non-ideators. All variables that were significantly different between suicide ideators and nonideators were included in the multiple logistic regression model in order to understand which variables are generally predictive of any suicidal ideation, when controlling for the influence of demographic factors and psychiatric symptoms. Additionally, this model which included the predictor variables and covariates was compared to a covariate-only model, in order to assess for any increased specificity the predictors added in identifying suicide ideators. Next, a stepwise multiple linear regression process was used to examine which masculine norms and suicidal desire variables were predictive of increased suicide severity in two un-adjusted models. A third multiple regression 
This is an author-produced, peer-reviewed version of this article. The final, definitive version of this document can be found online at The Journal of Men's Studies, published by SAGE Publications. Copyright restrictions may apply. doi: 10.1177/1060826519846428

model was then tested that also included demographic and psychiatric covariates in order to assess if any significant predictors from the unadjusted models remained significant when also controlling for demographic and psychiatric covariates.

Suicidal Ideation. One-way ANOV As were conducted to examine for group differences between suicide ideators and non-ideators and indicated that self-reliance $F(1,92)=18.94, p<.001$, risk-taking $F(1,92)=6.75, p<.05$, thwarted belongingness $F(1,92)=6.30, p<.05$, and perceived burdensomeness $F(1,92)=17.51, p<.001$ were significantly different between groups. Though not statistically significant, the first multiple logistic regression model that included six sociodemographic variables and symptoms of 13 psychiatric diagnoses correctly predicted $71.3 \%$ of participants, including 53.8\% of suicide ideators (see table 2 for a full model summary). The second multiple logistic regression model included the addition of risk-taking, self-reliance, thwarted belongingness, and perceived burdensomeness when accounting for the demographic and psychiatric covariates from the first model (see Table 3 for a full model summary). The model including both the predictor variables and covariates was significantly predictive of $69.2 \%$ of suicide ideators and correctly identified $81.9 \%$ of participants (see Table 3 for a full summary). Within the second model, both conformity to the norm and self-reliance and participant race were predictive of experiencing suicidal ideation. 
This is an author-produced, peer-reviewed version of this article. The final, definitive version of this document can be found online at The

Journal of Men's Studies, published by SAGE Publications. Copyright restrictions may apply. doi: 10.1177/1060826519846428

Table 2

Logistic Regression Model Predicting Suicide Ideation Status, Demographic and Diagnostic Covariates Only

\begin{tabular}{|c|c|c|c|c|}
\hline Variable & $B$ & $S E B$ & $O R$ & $95 \% \mathrm{CI}$ \\
\hline Relationship Status & -.25 & .54 & 1.27 & $.45-3.7$ \\
\hline Sexual Orientation & .36 & .85 & .70 & $.13-3.71$ \\
\hline Race & .96 & .75 & .38 & $.09-1.67$ \\
\hline Employment & -.38 & .77 & .62 & $.33-6.63$ \\
\hline Income & .00 & .00 & 1.00 & $1.00-1.00$ \\
\hline Age & .00 & .02 & 1.00 & $.95-1.05$ \\
\hline Depression & $.15^{*}$ & .06 & 1.16 & $1.03-1.31$ \\
\hline Posttraumatic Stress & .01 & .05 & 1.01 & $.91-1.12$ \\
\hline Eating Disorder Behaviors & -.12 & .14 & .89 & $.68-1.16$ \\
\hline $\begin{array}{l}\text { Obsessive Compulsive } \\
\text { Disorder }\end{array}$ & -.06 & .13 & .94 & $.74-1.20$ \\
\hline Panic Disorder & .10 & .14 & 1.10 & $.84-1.44$ \\
\hline Agoraphobia & -.16 & .12 & .85 & $.67-1.07$ \\
\hline Social Phobia & -.02 & .10 & .98 & $.82-1.17$ \\
\hline Alcohol Abuse & .05 & .13 & 1.05 & $.82-1.34$ \\
\hline Drug Abuse & -.01 & .19 & .99 & $.69-1.43$ \\
\hline Generalized Anxiety Disorder & .07 & .10 & 1.08 & $.88-1.34$ \\
\hline Somatization & .16 & .29 & 1.18 & $.66-2.09$ \\
\hline Hypochondriasis & .06 & .25 & 1.06 & $.65-1.73$ \\
\hline Psychosis & -.00 & .27 & 1.00 & $.59-1.69$ \\
\hline$X^{2}(d f)$ & & & & $24.36(19)$ \\
\hline
\end{tabular}


Table 3

Logistic Regression Model Predicting Suicide Ideation Status Including Predictor Variables, Demographics, and Diagnostic Covariates

\begin{tabular}{|c|c|c|c|c|}
\hline Variable & $B$ & $S E B$ & $O R$ & $95 \% C I$ \\
\hline Relationship Status & -.14 & .69 & 1.15 & $.30-4.43$ \\
\hline Sexual Orientation & .01 & 1.13 & .99 & $.12-8.99$ \\
\hline Race & $2.00 *$ & 1.01 & .13 & $.02-.97$ \\
\hline Employment & -.64 & .92 & 1.89 & $.31-11.38$ \\
\hline Income & .00 & .00 & 1.00 & $1.00-1.00$ \\
\hline Age & .02 & .03 & 1.02 & $.96-1.08$ \\
\hline Depression & .14 & .07 & 1.15 & $.99-1.33$ \\
\hline PTSD & -.04 & .06 & .96 & $.85-1.09$ \\
\hline Eating Disorder Behaviors & .02 & .19 & 1.02 & $.71-1.47$ \\
\hline $\begin{array}{l}\text { Obsessive Compulsive } \\
\text { Disorder }\end{array}$ & -.05 & .12 & .95 & $.75-1.21$ \\
\hline Panic Disorder & .05 & .17 & 1.06 & $.75-1.48$ \\
\hline Agoraphobia & -.28 & .16 & .75 & $.55-1.03$ \\
\hline Social Phobia & -.08 & .12 & .92 & $.73-1.18$ \\
\hline Alcohol Abuse & .00 & .15 & 1.00 & $.76-1.33$ \\
\hline Drug Abuse & -.27 & .27 & .76 & $.45-1.30$ \\
\hline Generalized Anxiety Disorder & .13 & .15 & 1.14 & $.85-1.53$ \\
\hline Somatization & .20 & .40 & 1.21 & $.55-2.67$ \\
\hline Hypochondriasis & -.23 & .33 & .79 & $.41-1.51$ \\
\hline Psychosis & -.10 & .33 & .90 & $.48-1.70$ \\
\hline Self-Reliance & $.44^{*}$ & .15 & 1.56 & $1.16-2.10$ \\
\hline Risk-Taking & .25 & .13 & 1.28 & $.99-1.66$ \\
\hline
\end{tabular}




\begin{tabular}{l|l|l|l|c} 
Perceived Burdensomeness & .08 & .06 & 1.08 & $.97-1.23$ \\
Thwarted Belongingness & .02 & .03 & 1.02 & $.96-1.07$ \\
$X^{2}(d f)$ & & & & $45.69(23)^{*}$ \\
\hline$*_{p}<.05$ & & &
\end{tabular}

Suicide Severity. Stepwise multiple regression was used to examine the ability of the predictor variables of conformity to hegemonic masculine norms, perceived burdensomeness, and thwarted belongingness to predict severity of suicidal ideation. The final model tested the ability of the variables to predict suicidal ideation when accounting for psychiatric and demographic covariates. The first model included men's conformity to all masculine norms, and the model was not predictive of severity of suicidal ideation (see Table 4). In the second step, perceived burdensomeness and thwarted belongingness were added as predictors in order to test if their addition improved the model. Model two, which included all masculine norms and suicidal desire variables, was significantly predictive of suicidal ideation and a significant improvement on model one $\left(R^{2}=.66, p<.001 ; \Delta R^{2}=.35, p<.001\right)$. Notably, within model two, perceived burdensomeness was a strong predictor of suicidal ideation $(\beta=.84, p<.001)$. However, in the third step, when all demographic covariates were added, perceived burdensomeness no longer significantly predicted suicidal ideation (see Table 4).

Table 4

Summary of Stepwise Multiple Regression Models Predicting Severity of Suicidal Ideation

\begin{tabular}{|c|c|c|c|c|}
\hline Variable & B & SE B & $\begin{array}{c}95 \% \text { CI for } \\
\text { B }\end{array}$ & $\beta$ \\
\hline \multicolumn{5}{|l|}{ Model 1} \\
\hline Winning & .17 & .60 & $-1.06-1.38$ & .07 \\
\hline Emotional Control & -.90 & .76 & $-2.45-.65$ & -.40 \\
\hline Risk Taking & -.39 & .39 & $-1.19-.41$ & -.21 \\
\hline Violence & .42 & .31 & $-.22-1.06$ & .23 \\
\hline Power over Women & -.49 & .72 & $-1.95-.97$ & -.13 \\
\hline Playboy & 1.22 & .61 & $-.03-2.47$ & .36 \\
\hline Self-Reliance & 1.33 & .90 & $-.50-3.16$ & .48 \\
\hline Primacy of Work & -.25 & .68 & $-1.63-1.14$ & -.07 \\
\hline Heterosexual Presentation & -.13 & .34 & $-.82-.56$ & -.07 \\
\hline \multicolumn{5}{|l|}{ Model 2} \\
\hline Winning & -.69 & .47 & $-.16-.27$ & -.30 \\
\hline Emotional Control & -.12 & .58 & $-1.30-1.06$ & -.05 \\
\hline Risk Taking & -.41 & .29 & $-1.01-.18$ & -.22 \\
\hline Violence & .38 & .23 & $-.10-.86$ & .21 \\
\hline Power Over Women & .45 & .56 & $-.70-1.60$ & .12 \\
\hline Playboy & .20 & .48 & $-.79-1.19$ & .06 \\
\hline Self-Reliance & .16 & .69 & $-1.26-1.58$ & .06 \\
\hline Primacy of Work & .19 & .50 & $-.84-1.22$ & .06 \\
\hline Heterosexual Presentation & -.23 & .25 & $-.74-.27$ & -.12 \\
\hline Thwarted Belongingness & -.09 & .09 & $-.27-.09$ & -.15 \\
\hline Perceived Burdensomeness & .65 & .13 & $.39-.91$ & $.84 * *$ \\
\hline Model 3 & & & & \\
\hline
\end{tabular}




\begin{tabular}{l|c|c|c|c} 
Winning & -1.23 & .94 & $-.30-.83$ & -.55 \\
Emotional Control & .39 & 1.01 & $-1.82-2.61$ & .18 \\
Risk-Taking & -.31 & .49 & $-1.38-.76$ & -.63 \\
Violence & .28 & .55 & $-.93-1.48$ & .50 \\
Power Over Women & .28 & 1.37 & $-2.73-3.28$ & .20 \\
Playboy & .72 & .98 & $-1.44-2.88$ & .21 \\
Self-Reliance & -.61 & 1.11 & $-3.05-1.82$ & -.22 \\
Primacy of Work & 1.03 & 1.01 & $-1.19-3.25$ & .31 \\
Heterosexual Presentation & -.33 & .55 & $-1.54-.88$ & -.17 \\
Thwarted Belongingness & -.04 & .14 & $-.34-.28$ & .66 \\
Perceived Burdensomeness & .52 & .26 & $-.06-1.09$ & -.05 \\
Depression & .21 & .46 & $.80-1.22$ & .15 \\
Posttraumatic Stress & .35 & .43 & $-.60-1.29$ & .22 \\
Eating Disorder Behaviors & -.83 & 1.32 & $-3.73-2.07$ & -.20 \\
Obsessive Compulsive Disorder & -.37 & 1.04 & $-2.66-1.93$ & -.08 \\
Panic Disorder & 1.26 & 1.41 & $-4.35-1.84$ & -.38 \\
Agoraphobia & -.45 & .66 & $-1.90-1.01$ & -.19 \\
Social Phobia & .33 & .77 & $-1.37-2.02$ & .16 \\
Alcohol Abuse & .15 & .69 & $-1.36-1.66$ & .04 \\
Drug Abuse & .41 & 1.64 & $-3.20-4.03$ & .08 \\
Generalized Anxiety & -.08 & .76 & $-1.75-1.58$ & -.04 \\
Somatization & 2.22 & 2.25 & $-2.73-7.16$ & .32 \\
Hypochondriasis & .30 & 1.39 & $-2.76-3.37$ & .05 \\
Psychosis & 2.43 & 1.78 & $-1.48-6.34$ & .32 \\
Sexual Orientation & -2.11 & 7.25 & $-18.07-13.84$ & -.07 \\
Race & -2.05 & 7.93 & $-19.51-15.40$ & -.08 \\
Employment & -.63 & 5.38 & $-12.48-11.21$ & -.03 \\
Relationship Status & .45 & 3.55 & $-7.37-8.27$ & .03 \\
Age & -.10 & .25 & $-.65-.45$ & -.13 \\
Income & .00 & .00 & $-.00-.00$ & -.07 \\
\hline
\end{tabular}

Note: Model $1\left(R=.55, R^{2}=.31, p=.17\right) ;$ Model $2\left(R=.81 ; R^{2}=.66, p<.001 ; \Delta R^{2}=.35, p<.001\right) ;$ Model $3(R=$ $\left..91 ; R^{2}=.83, p=.41 ; \Delta R^{2}=.18, p=.82\right)$;

\section{Discussion}

To date, no other study has investigated how suicidal ideation is predicted with models that integrate conformity to hegemonic masculine norms and interpersonal risk factors for suicidal desire in a sample of men at high risk for suicidal behaviors. Overall, the logistic regression analyses indicated that the integration of men's conformity to specific masculine norms as well as their levels of perceived burdensomeness and thwarted belongingness more accurately predicts which men experience suicidal ideation, compared to psychiatric symptoms and demographics alone.

Furthermore, the first analysis partially supported the hypothesis that the variables self-reliance, playboy, violence, perceived burdensomeness, and thwarted belongingness would predict suicidal ideation since self-reliance was the only variable predictive of suicidal ideation when controlling for demographic and psychiatric covariates. The finding that self-reliance was predictive of suicidal ideation is noteworthy though, because this result is consistent with other research on gendered risk factors for suicide in men. In their recent investigation of men's conformity to masculine norms and suicidal ideation, Pirkis et al. (2017) also found self-reliance to be the only gender-related predictor of 
suicidal ideation in a national sample of Australian men. While Pirkis et al. did not also explore specific pathways regarding how men's self-reliance increased their risk for suicidal ideation, they hypothesized that self-reliant attitudes likely increase men's suicide risk because they impede help-seeking behaviors.

Additionally, in their latent class analysis of men's conformity to masculine norms and reported levels of psychological distress, Wong, Owen, \& Shea (2012) classified a group of men termed "detached risk takers" (p. 179). A certain profile of detached risk takers reported stronger conformity to the norms of self-reliance, risk-taking, and playboy, and these men were more likely to report experiencing psychological distress. Wong et al. (2012) further note that the detached risk takers' emphasis on self-reliance may leave them interpersonally isolated which further increases this group's vulnerability to distress. The findings from this study indicate that experiencing suicidal ideation may be a highly concerning type of psychological distress for men such men who conform to the norm of self-reliance.

The hypothesis that perceived burdensomeness and thwarted belongingness would predict the existence and severity of suicidal ideation was partially supported, as perceived burdensomeness was strongly predictive of suicidal ideation in the model that included all masculine norms and suicidal desire variables; however, perceived burdensomeness was not predictive of suicide ideation severity when controlling for demographic and psychiatric covariates. Overall, these results appear to further support the saliency of the construct of perceived burdensomeness to the interpersonal theory of suicide, and that burdensomeness may be the more robust of the suicidal desire-related variables in the interpersonal theory of suicide (Bryan, Morrow, Anestis, \& Joiner, 2010; Chu et al., 2018). Alternatively, the results suggest that when accounting for a range of other factors also historically indicative of suicide (e.g. diagnosis, age, race, employment, etc.), perceived burdensomeness may not be the most robust overall predictor of either the existence or severity of suicidal ideation.

\section{$\underline{\text { Limitations and Future Directions }}$}

The findings of this study assist with the first steps of integrating masculinity with suicidal desire in the prediction of suicidal ideation in men at high risk for suicide. Future research methodologies that allow for a causal or multidirectional understanding of these variables will allow for a more accurate understanding of the nature of suicidality and masculinity in men at high risk for suicide. For example, in homeless men, research that examines if men who conform to hegemonic norms such as self-reliance tend to experience suicidal ideation prior to or after becoming homeless, could inform when and what types of early prevention efforts might be most effective.

The interpersonal theory of suicide was also not comprehensively measured in this study, in that we did not investigate both the acquired capability for suicide as well as the interpersonal factors that are important to the development of the desire for suicide. Future studies that include an investigation of the detailed relationships between hegemonic masculine norms with both the acquired capability for suicide as well as perceived burdensomeness and thwarted belongingness will provide a broader perspective of suicidality and gender in at risk men. Moreover, this study included an examination of conformity to masculine norms, suicidal desire, and suicidal ideation when accounting when a comprehensive range of psychiatric covariates. While this methodology allowed for testing of predictive models when accounting for a number of confounding variables, in reality, individuals likely experience fewer overall symptoms at any given time. Future research focused on assessing how suicidal desire and masculinity is associated with specific diagnoses may further our understanding of how these variables are differentially related with various psychological disorders.

Additionally, this study focused on a relatively small and homogenous group of homeless men. Granted, men in particular, are difficult to recruit for human subjects research and a transient population, such as homeless men, also present with challenges associated with recruitment and sampling. Regardless, the primarily White, heterosexual, nonveteran sample is certainly not representative of all homeless men, and additional research is needed to broadly understand suicide risk in men who are homeless. However, our hope is that the findings of this study provide some tentative conclusions that will inform future research on suicide in men. 


\section{References}

Beck, A.T., \& Steer, R.A. Beck Scale for Suicidal Ideation: Manual. Bloomington, MN: Pearson.

Beck, A.T., Steer, R.A., \& Ranieri, W.F. (1988). Scale for suicidal ideation: Psychometric properties of a self-report version. Journal of Clinical Psychology, 44, 499-505.

Burns, S.M. \& Mahalik, J.M. (2011). Suicide and Dominant Masculinity Norms Among Current and Former United States Military Servicemen. Psychology of Men and Masculinity, 5, 347-353. DOI: 10.1037/a0025163

Bryan, C.J., Morrow, C.E., Anestis, M.D., \& Joiner, T.E. (2010). A preliminary test of the interpersonalpsychological theory of suicidal behavior in a military sample. Personality and Individual Differences, 48, 347-350.

Callanan, V. J., \& Davis, M. S. (2012). Gender differences in suicide methods. Social Psychiatry and Psychiatric Epidemiology, 47(6), 857-869. doi:10.1007/s00127-011-0393-5.

Canetto, S.S., \& Sakinofsky, I. (1998). The gender paradox in suicide. Suicide and Life Threatening Behavior, 28, 123.

Centers for Disease Control and Prevention. (2015). Suicide: Facts at a Glance. Retrieved from: https://www.cdc.gov/violenceprevention/pdf/suicide-datasheet-a.pdf

Chu, C., Stanley, I.H. Greenberg, J.H., Walker, K.L., Hirsch, J.K., Rudd, M.D. (2018). Perceived problem-solving deficits and suicidal ideation: Evidence for the explanatory roles of thwarted belongingness and perceived burdensomeness in five samples. Journal of Personality and Social Psychology, 115, 137-160.

Chu, C., Tucker, R.P., Patros, C.H., Buchman-Schmitt, J.M., Stanley, I.H., Hom, M.A., ...\& Joiner, T.E. (2017). The interpersonal theory of suicide: A systematic review and meta-analysis of a decade of cross-national research. Psychological Bulletin, 143, 1313-1345.

Coleman, D. (2015). Traditional Masculinity as a Risk Factor for Suicidal Ideation: Cross-Sectional and Prospective Evidence from a Study of Young Adults. Archives of Suicide Research, 19, 366-384. DOI: 10.1080/13811118.2014.957453

Coleman, D., Kaplan, M., \& Casey, J. (2011). The social nature of male suicide: A new analytic model. International Journal of Men's Health, 10, 240-252.

Conner, K.R., Cerulli, C., \& Caine, E.D. (2002). Threatened and attempted suicide by partner-violent male respondents petitioned to family violence court. Violence and Victims, 17, 115-125.

Dahlen, E. R., \& Canetto, S. S. (2002). The role of gender and suicide precipitant in attitudes toward nonfatal suicidal behavior. Death Studies, 26(2), 99-116. doi:10.1080/074811802753455235

Deluty, R.H. (1988). Factors affecting the acceptability of suicide. Omega, 19, 315326.

Desai, R. A., Liu-Mares, W., Dausey, D. J., \& Rosenheck, R. A. (2003). Suicidal ideation and suicide attempts in a sample of homeless people with mental illness. Journal of Nervous and Mental Disease, 191(6), 365-371. doi:10.1097/00005053-200306000-00003

Easton, S.D., Renner, L.M., \& O’Leary, P. (2013). Suicide attempts among men with histories of child sexual abuse: Examining abuse severity, mental health, and masculine norms. Child Abuse and Neglect, 37, 380-387.

Eynan, R., Langley, J., Tolomiczenko, G., Rhodes, A.E., Links, P., Wasylenki, D., \& Goering, P. (2002). The association between homeless and suicidal ideation and behaviors: Results of a cross-sectional survey. Suicide \& Life-Threatening Behavior, 32, 418-427.

Genuchi, M. C. (2018). The role of masculinity and depressive symptoms in predicting suicidal ideation in homeless men. Archives of Suicide Research. https://doi.org/10.1080/13811118.2018.1428705.

Grenato, S.L., Smith, P.N., \& Selwyn, C.N. (2015). Acquired Capability and Masculine Gender Norm Adherence: Potential Pathways to Higher Rates of Male Suicide. Psychology of Men and Masculinity, 3, 246-253.

Hyer, J. (2017). Boise Metro Area: Workforce Trends. Retrieved from: https://labor.idaho.gov/publications/lmi/pubs/BoiseMSAprofile.pdf.

Joiner, T. (2005). Why people die by suicide. Cambridge, MA: Harvard University Press.

Lewis, R. J., \& Shepeard, G. (1992). Inferred characteristics of successful suicides as a function of gender and context. Suicide and Life-Threatening Behavior, 22(2), 187-196.

Marks, A. (1988). Structural parameters of sex, race, age, and education and their influence on attitudes toward suicide. Omega: Journal of Death and Dying, 19(4), 327-336. doi:10.2190/B0F2-GY56-357X-K0RW

Noel, F., Moniruzzaman, A., Somers, J., Frankish, J., Strehlau, V., Schutz, C., Krausz, M. (2015). A longitudinal study of suicidal ideation among homeless, mentally ill individuals. Social Psychiatry and Psychiatric Epidemiology, 51, 107-114. 
This is an author-produced, peer-reviewed version of this article. The final, definitive version of this document can be found online at The Journal of Men's Studies, published by SAGE Publications. Copyright restrictions may apply. doi: 10.1177/1060826519846428

Parent, M. C., \& Moradi, B. (2009). Confirmatory factor analysis of the Conformity to Masculine Norms Inventory and development of the Conformity to Masculine Norms Inventory-46. Psychology of Men \& Masculinity, 10(3), 175-189. doi:10.1037/a0015481

Parent, M. C., \& Moradi, B. (2011). An abbreviated tool for assessing conformity to masculine norms: Psychometric properties of the Conformity to Masculine Norms Inventory-46. Psychology of Men \& Masculinity, 12(4), 339-353. doi:10.1037/a0021904

Pirkis, J., Spittal, M.J., Keogh, L., Mousaferiadis, T., \& Currier, D. (2017). Masculinity and suicidal ideation. Social Psychiatry and Psychiatric Epidemiology, 52, 319-327. doi: 10.1007/s00127-0016-1324-2.

Rich, A. R., Kirkpatrick-Smith, J., Bonner, R. L., \& Jans, F. (1992). Gender differences in the psychosocial correlates of suicidal ideation among adolescents. Suicide and Life-Threatening Behavior, 22(3), 364-373. doi: $10.1177 / 1557988309335823$.

Smith, P.N., \& Cukrowicz, K.C. (2010). Capable of suicide: A functional model of the acquired capability component of the interpersonal-psychology theory of suicide. Suicide and Life Threatening Behavior, 40, 266-275.

Susser, E., Struening, E.L., \& Conover, S. (1989). Psychiatric problems in homeless men. Lifetime psychosis, substance use, current distress in new arrivals at New York City shelters. Archives of General Psychiatry, $46,845-850$.

Van Orden, K.A., Cukrowicz, K.C., White, T.A., \& Joiner, T.E. (2012). Thwarted Belongingness and Perceived Burdensomeness: Construct Validity and Psychometric Properties of the Interpersonal Needs Questionnaire. Psychological Assessment, 24, 197-215.

Van Orden, K.A., Cukrowicz, K.C., Whitte, T.K., Braithwaite, S.R., Selby, E.A., \& Joiner, T.E. (2010). The interpersonal theory of suicide. Psychological Review, 117, 575-600.

Wong, Y. J., Owen, J., \& Shea, M. (2012). A latent class regression analysis of men's conformity to masculine norms and psychological distress. Journal of Counseling Psychology, 59(1), 176-183. doi:10.1037/a0026206

World Health Organization. (2015). Suicide rates (per 100,000 population), Global Health Observatory (GHO) data. Retrieved from: http://www.who.int/gho/mental_health/suicide_rates/en/

Zimmerman, M. (2002). The Psychiatric Diagnostic Screening Questionnaire: Manual. Los Angeles: Western Psychological Services.

Zimmerman, M., \& Mattia, J. I. (2001). The Psychiatric Diagnostic Screening Questionnaire: Development, reliability and validity. Comprehensive Psychiatry, 42, 175-189.

Zimmerman, M., \& Sheeran, T. (2003). Screening for principal versus comorbid conditions in psychiatric outpatients with the psychiatric diagnostic screening questionnaire. Psychological Assessment, 15, 110-114. doi: 10.1037/1040-3590.15.1.110. 